\title{
Application of BIM Technology in the Drawing Deepening Stage of China Port Museum
}

\author{
Wang Zhanliang, Tian Xiugang \\ Ningbo Construction Co. Ltd., Ningbo, China \\ Email address: \\ 68235426@qq.com (Wang Zhanliang),2439826500@qq.com (Tian Xiugang)
}

\section{To cite this article:}

Wang Zhanliang, Tian Xiugang. Application of BIM Technology in the Drawing Deepening Stage of China Port Museum. International Journal of Civil, Construction and Environmental Engineering. Vol. 3, No. 3, 2018, pp. 53-63. doi: 10.11648/j.jccee.20180303.12

Received: June 5, 2018; Accepted: July 6, 2018; Published: August 1, 2018

\begin{abstract}
Combined with the project of China Port Museum, the Paper has mainly introduced the application of BIM technology in the stage of deepening design of complex architecture projects. Through the three-dimensional model, it can quickly find and solve the contradictions and design mistakes in the drawings, having perfected the structure system, optimized the details, improved the efficiency and accuracy of the project's deepening design and guaranteed the correctness of the subsequent component processing and the smooth progress of site installation.
\end{abstract}

Keywords: Information, Bionic Architecture, Modeling, Building Information Modeling (BIM), Application

\section{Introduction}

The project of China Port Museum and National Underwater Cultural Heritage Protection Center, Ningbo Base, is a typical biotic architecture with its overall architectural shape like a small shell next to two conches on the beach. In the project design, the architectural design, the structural design, the design in steel structure profession and the curtain wall design, etc., are divided into different teams. If each profession is divided into separate unit without a common platform to communicate, it was bound to be incompatible and there would even be unimaginable consequences. However, the application of BIM technology integrates the information in each profession into a modeling where the cohesion and coordination among each profession as well as the contradiction among each other and the contradictions among each profession will be clearly and intuitively reflected, which will bring great convenience for solving both the problems in each profession itself and the contradictory problems among each profession and will also provide a more intuitive basis for the interaction and coordination among each profession. Due to the structural features of the project itself, it is only BIM technology that can be used to successfully accomplish the design and construction of several professions such as architecture, civil structures, steel structure, curtain wall and electromechanics.

\section{General}

The project of China Port Museum and National Underwater Cultural Heritage Protection Center, Ningbo Base, is divided into zone $\mathrm{A}, \mathrm{B}, \mathrm{C}$ and $\mathrm{D}$ by function, with an overall floorage (gross floor area) of 40,987 $\mathrm{m}^{2}$ and a maximum height of $58 \mathrm{~m}$. The zone A and B are shaped like a large and small conch, while the zone $C$ is just like a small shell. The zone $\mathrm{A}, \mathrm{B}$, and $\mathrm{C}$ are connected into a whole by zone $\mathrm{D}$, in which they are functionally independent and connected. And the shape is not only unique but also integrated, with the overall architectural shape like a small shell next to two conches on the beach (as shown in Figure 1). 


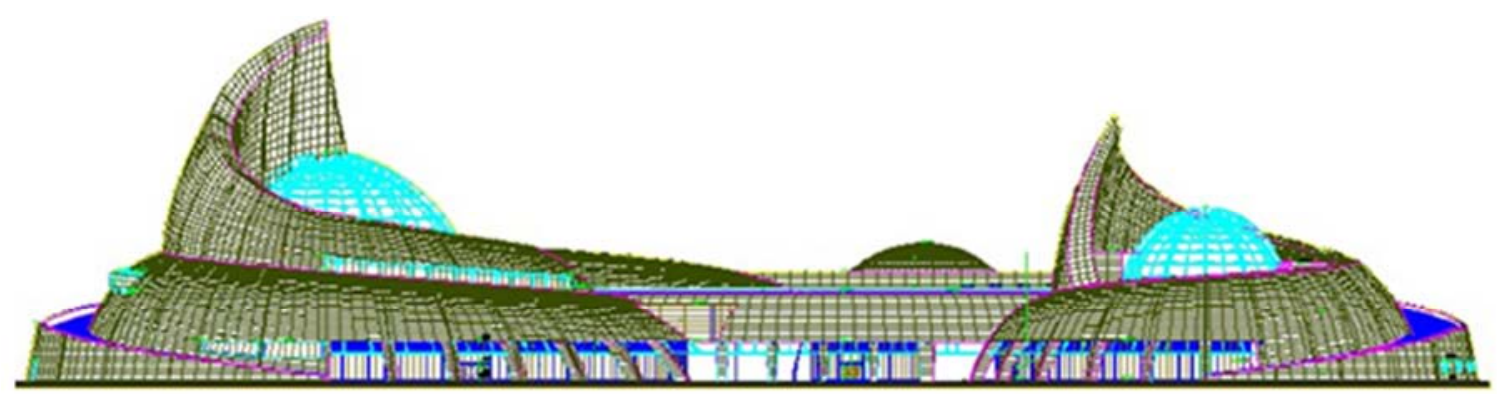

a. Front elevation.

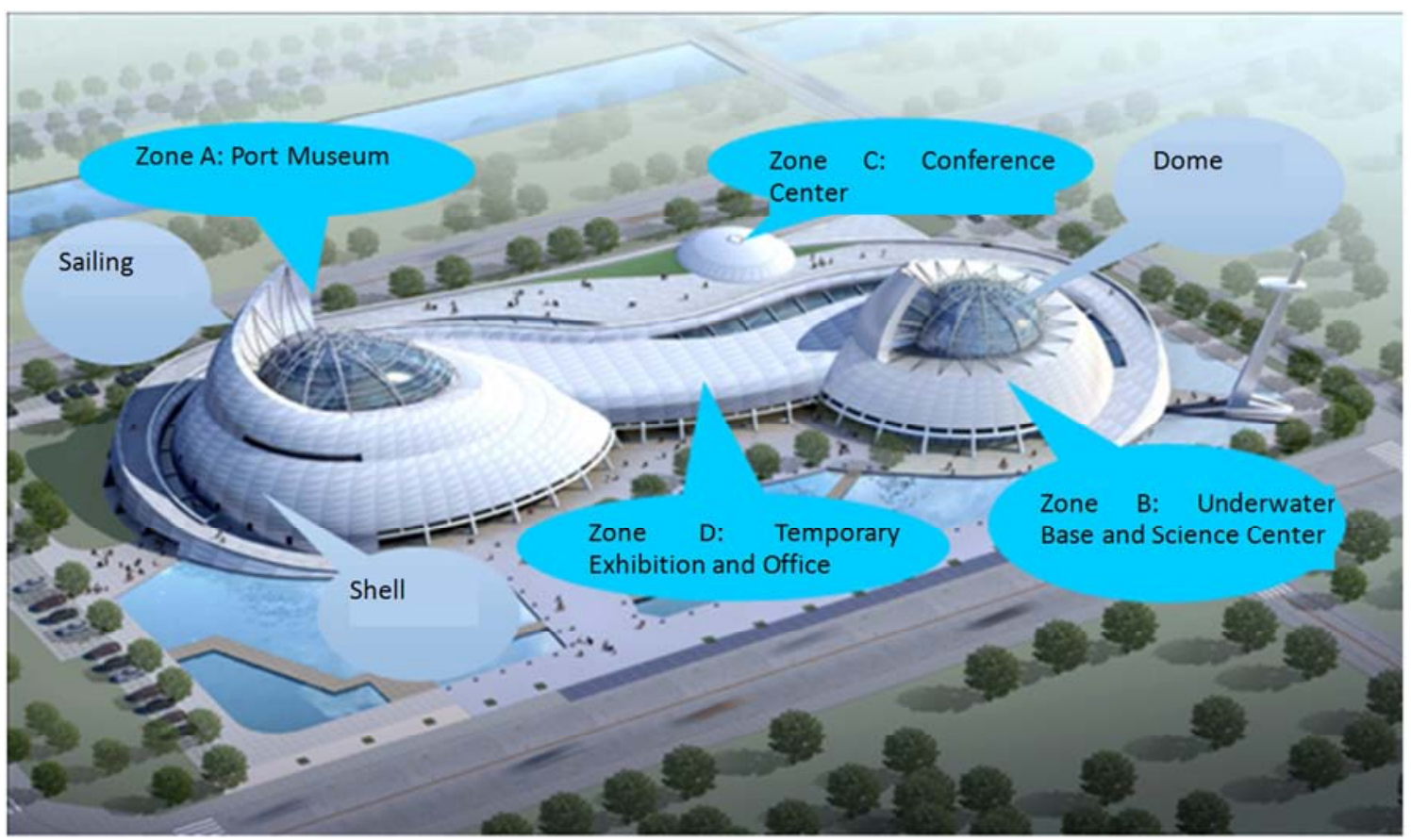

b. Overall modeling.

Figure 1. Architecture effect and function distribution.

The zone $\mathrm{D}$ of this building is a reinforced concrete frame structure; the zone $\mathrm{C}$ is a steel dome structure; the lower part of zone $\mathrm{A}$ and $\mathrm{B}$, that is, the conch, is the main part, the inside of which is a steel-reinforced concrete structure, while the lower part of the outer shell is an arc steel-reinforced concrete column and the upper part of the shell is transformed into an arc-box steel-reinforced column in the transition section connected with the upper sailing, where the arc steel bridging

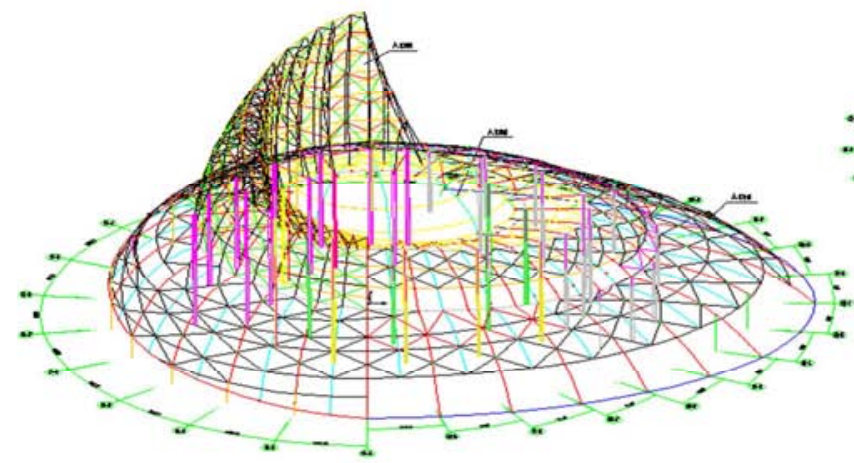

is provided between the columns. The upper sailing structure of the building, that is, the conch tail, is composed of an abnormal-shape vertical steel truss and a horizontal steel truss, and the dome is composed of a vertical arc steel column, a ring horizontal steel support and a top box-like disc component. Figure 2 is an isometric drawing for the overall structure of steel structure

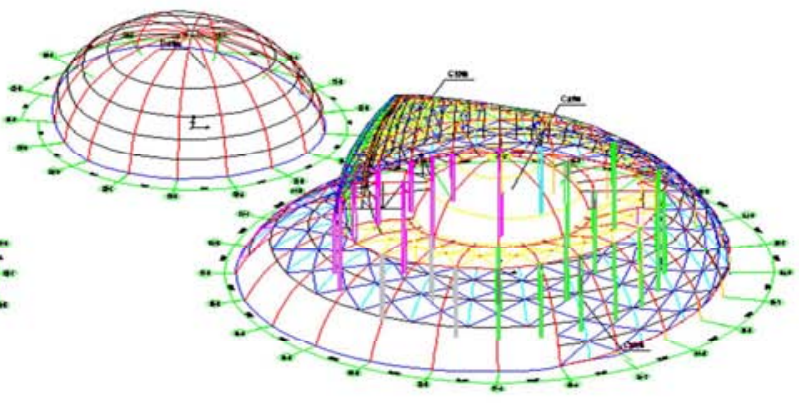

Figure 2. Isometric drawing of steel structure. 


\section{Structural Features}

\subsection{Profile Positioning of Building}

The profile of this building is represented by the three-dimensional coordinates of 2296 feature control points, of which the conch shell is represented by the three-dimensional coordinates of the feature control points on the outer surface of the outer contour skeleton, and the conch tail is represented by the three-dimensional coordinates of the feature control points on the center line of the upper steel pole, that is, the whole profile of the architectural modeling can be formed by connecting the adjacent coordinates points of the design. If the adjacent three points are in the same arc, the modeling to be represented in the design will be more rounded and more close to the design intent. [12]

\subsection{Outer Profile Features of Building}

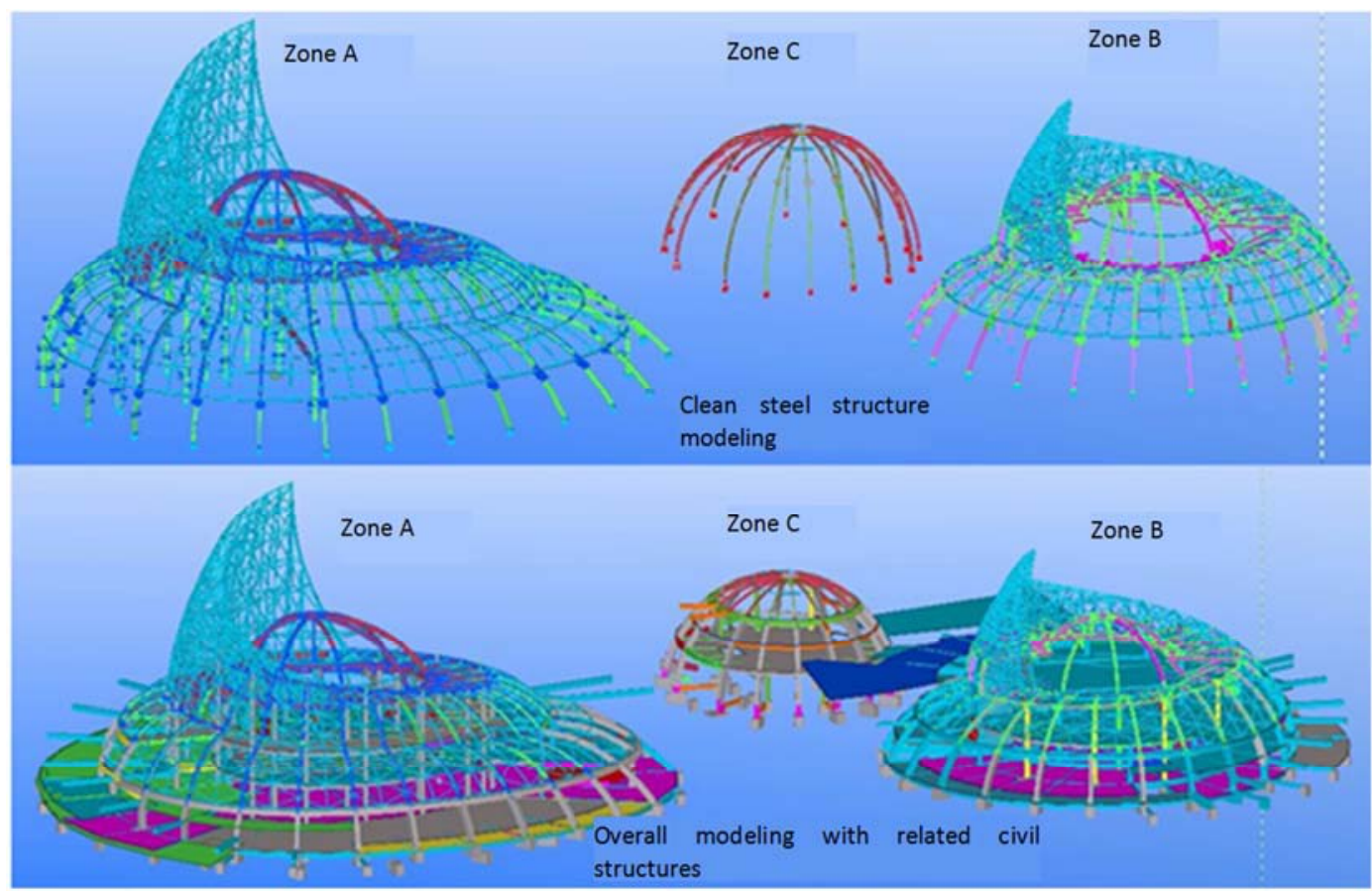

a. Overall modeling of structure.

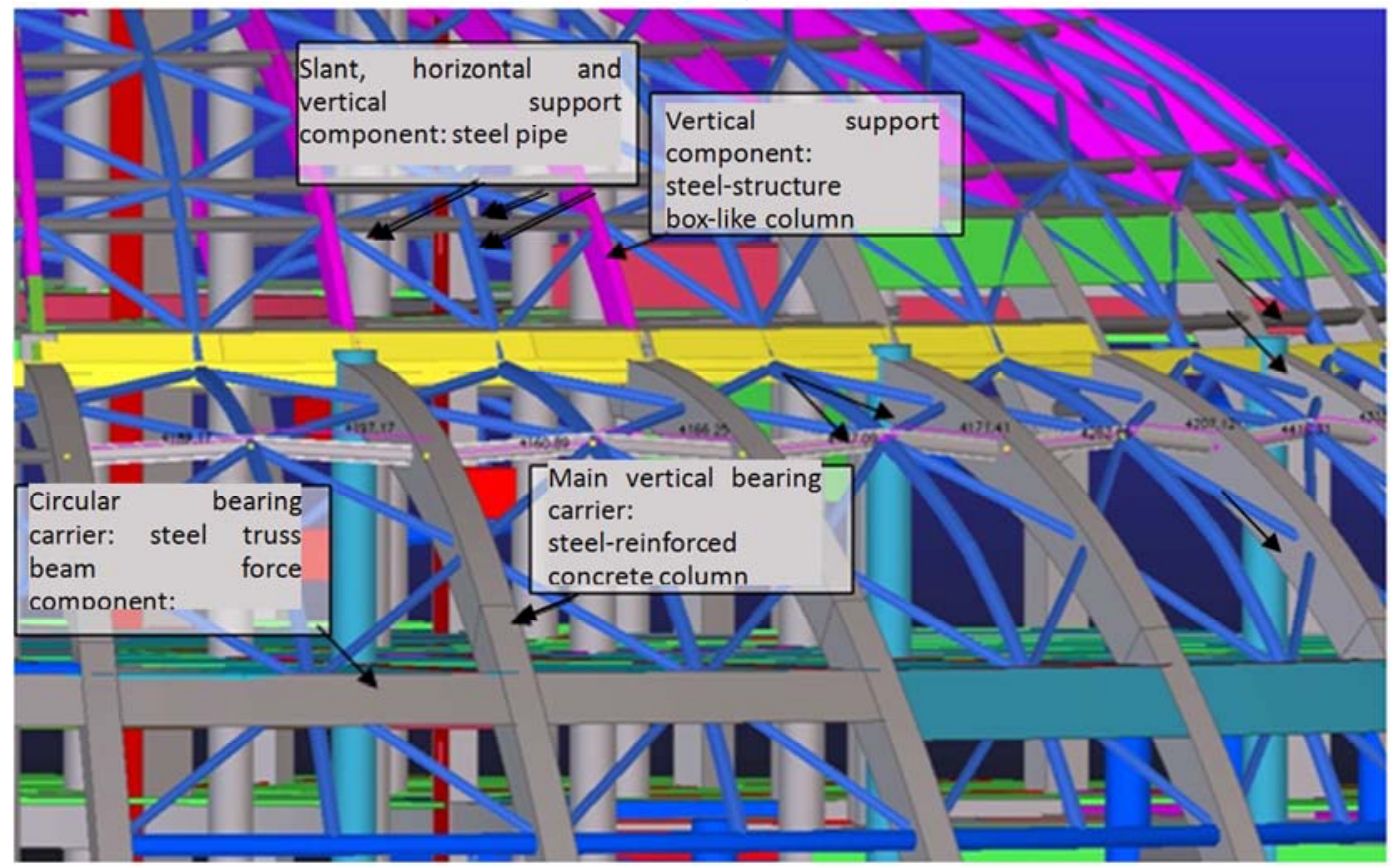

b. Partial enlarged view for the shell.

Figure 3. Overall structure modeling and partial discharge of shel $l$. 
The vertical bearing carriers of the building's outer frame are divided into 3 sections, where the arc 1 at the bottom is made of a steel reinforced concrete column with a built-in I-steel reinforcement, the section on the top of the arc 1 is converted to a box-steel component, and the top, that is, the conch tail, is the steel pipe. The mesh-like arc steel support components are designed between the vertical bearing carriers, which do not only reduce the effective length of the vertical bearing carriers and increase the out-of-plane stability and bearing capacity of the vertical bearing carriers, but also provide a bearing hold for the curtain wall keel. Figure 3 is a partial enlarged view for the overall modeling and shell of the structure.

\section{Application of BIM Technology in Deepening Stage}

How to make the shape of the building more smooth and rounded as well as more in line with the design requirements is the goal that construction must ensure. For such complex modeling and structures, if we only depend on conventional technologies, it is not only difficult to achieve the design effect, but also there will be a lot of contradictions and errors in the internal structure. Therefore, we use the BIM overall modeling technology to build the structure, architecture and curtain wall to an overall modeling to find and solve the contradictions in design and possible problems in construction in its own modeling, modeling comparison and model fitting.[8]

\subsection{Overall Modeling}

\subsubsection{Software Used in Modeling}

Tekla-Structures 16.1 software is used in steel Structures and concrete; Rhinoceros 4.0 software is used in architecture and curtain wall; Revit 2014 software is used in electromechanics. [7]

\subsubsection{Modeling Technology of Steel Structure}

Import the data of 2296 three-dimensional coordinate points given by the Design Institute into an Excel to convert them into the spatial coordinate point of $(x, y, z)$. Use the "Draw-Point-Multipoint" command in AutoCAD to copy all coordinate data in the Excel and paste them into the CAD command line, and enter these control points into the corresponding coordinates of CAD to form the outer contour composed of control points. Trace these points in a way that three points share the same arc to form the outer contour of the architecture and save these CAD files as "kj. dxf". In the Tekla Structures, set and apply the section property of the beam to D12 and apply it, import the CAD file by "file-input-DXF", enter the option to create the selection "parts" and section D12 of the beam, and click "input". In this way, the outer contour of the architecture is quickly created into Tekla. [9]

\subsection{Problems Found and to Be Solved in Overall Modeling of Steel Structure}

\subsubsection{Coordinate Offset}

In general, on the basis of the contour line generation above, modify the section property of the bar on each part or draw it in segments and then refine the joints, so that the entire steel structure modeling can be established. However, in the Project, the coordinates of the shell's lower part are given to the concrete surface, so that there are no control points in steel-structure skeleton of the steel-reinforced concrete structure, that is, the steel structure modeling of the steel-reinforced concrete is not completed. To solve this problem, first, offset the coordinate to transform the contour line of concrete surface into the contour line of the built-in steel reinforcement. In this project, the concrete surface of the steel reinforced concrete at the lower part of the arc outer frame column is $225 \mathrm{~mm}$ away from the surface of the steel reinforcement. Therefore, the positioning of the built-in steel reinforcement is that the outer surface of the arc column's concrete moves $225 \mathrm{~mm}$ inward along the normal direction. After such an offset, the steel components between the steel columns and the built-in steel reinforcement are separated. In order to intersect the center line of the steel pipe with the center line of the steel reinforcement, it is necessary to offset both ends of the pipes again. The offset is implemented in 6 steps: as shown in Figure 4.

1) Offset the inner and outer surfaces of the steel-reinforced concrete arc column by $225 \mathrm{~mm}$ inward the column to be the outer surface of the steel reinforcement;

2) Offset the lowermost ring steel pipe to a certain distance inward (horizontally), so that the minimum distance between the upper surface of the steel pipe and the upper surface of the steel-reinforced-concrete column is 50 to facilitate the welding with the embedded parts;

3) Offset the intersection between the other horizontal and slant support pipes in the shell and the vertical arc steel-reinforced column to a certain distance inward along the normal, so that the minimum distance between the upper surface of the steel pipe and the surface of the arc column is $50 \mathrm{~mm}$.

4) Place the outer surface of the radial arc pipe on the coordinates given by the structure;

5) Directly pull the end points of the radial steel pipe to a point where it can intersect with the lowermost steel pipe to form a closed structure;

6) Pull the horizontal and slant support rods to the relevant positions of the radial arc steel pipe to ensure that the pipes are welded together.

After the offset of the steps above, the modeling of the steel structure has met the design requirements. 


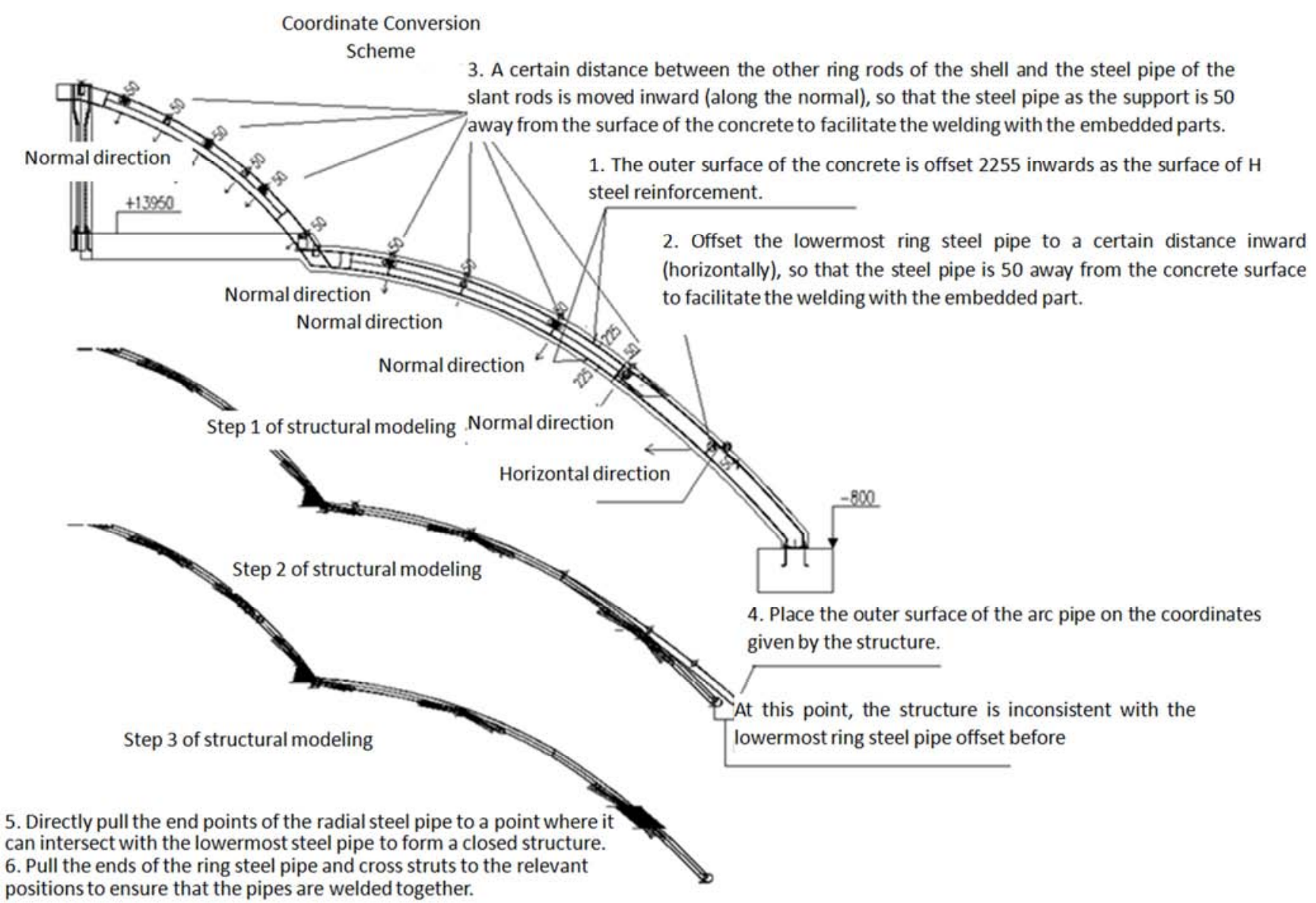

Figure 4. Coordinate conversion scheme.

\subsubsection{Perfection of Steel Structure System}

As a bionic architecture, this project has its unique complexity. The problems in the design are difficult to find in the CAD graphic software. At present, only through the overall modeling technology can the entire structure be displayed completely, and the defects in the structure will be completely shown by browsing the entire architecture once time with the roaming function.

After the establishment of the modeling, the following problems have been found by roaming the entire modeling: (1) a large number of rods on the inside of the sailing have offset the position planned in the design. The nodes where some rods have been converged have offset the bear, as shown in Figure $5 \mathrm{a}$; some rods used as the supports have offset the vertical bearing carrier, as shown in Figure 5b; (2) extra components have appeared at individual locations, as shown in Figure 5c; (3) some vertical bearing carriers have not fallen on the support, as shown in Figure 5d; (4) the partial absence of the steel structure system has made the entire structural system imperfect, as shown in Figure 5e.

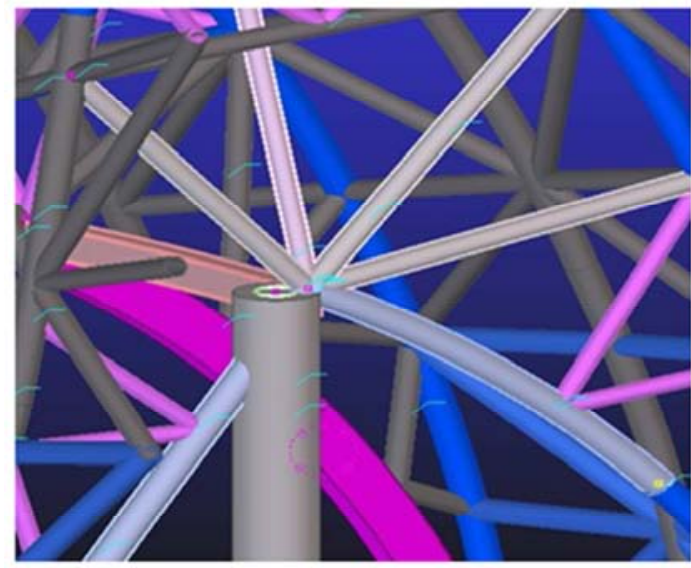

a. Joint offsetting support.

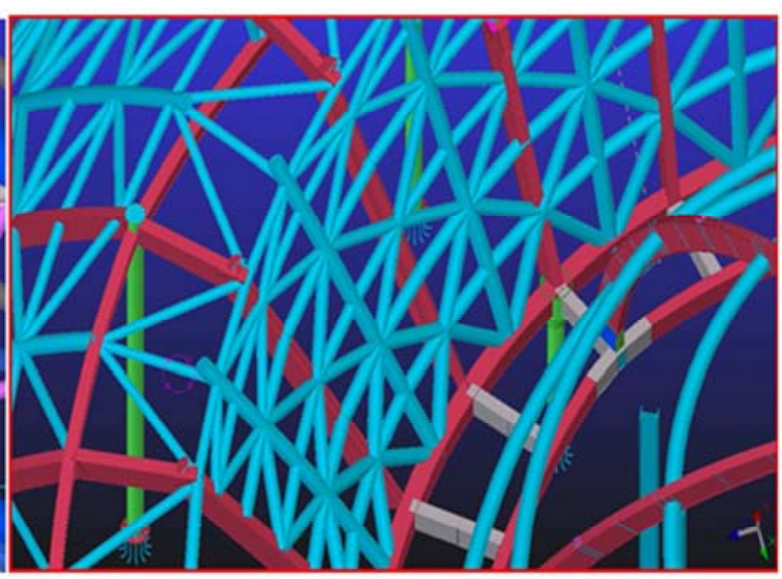

b. Sailing pipes separating from frame structure. 


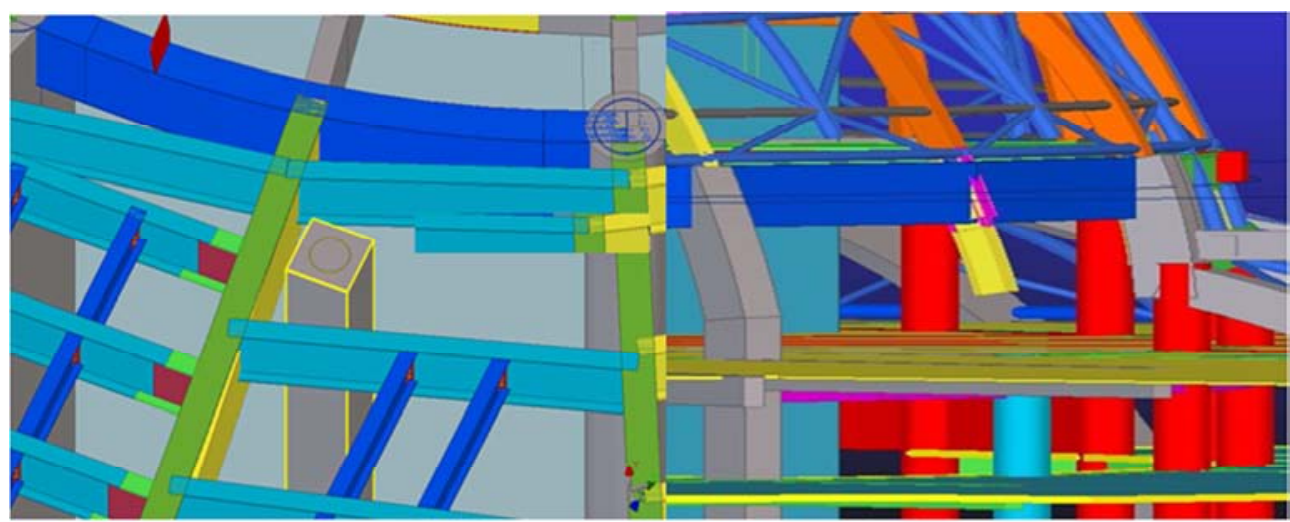

c. Redundant steel columns.

d. Hanging of steel columns without fulcrum.

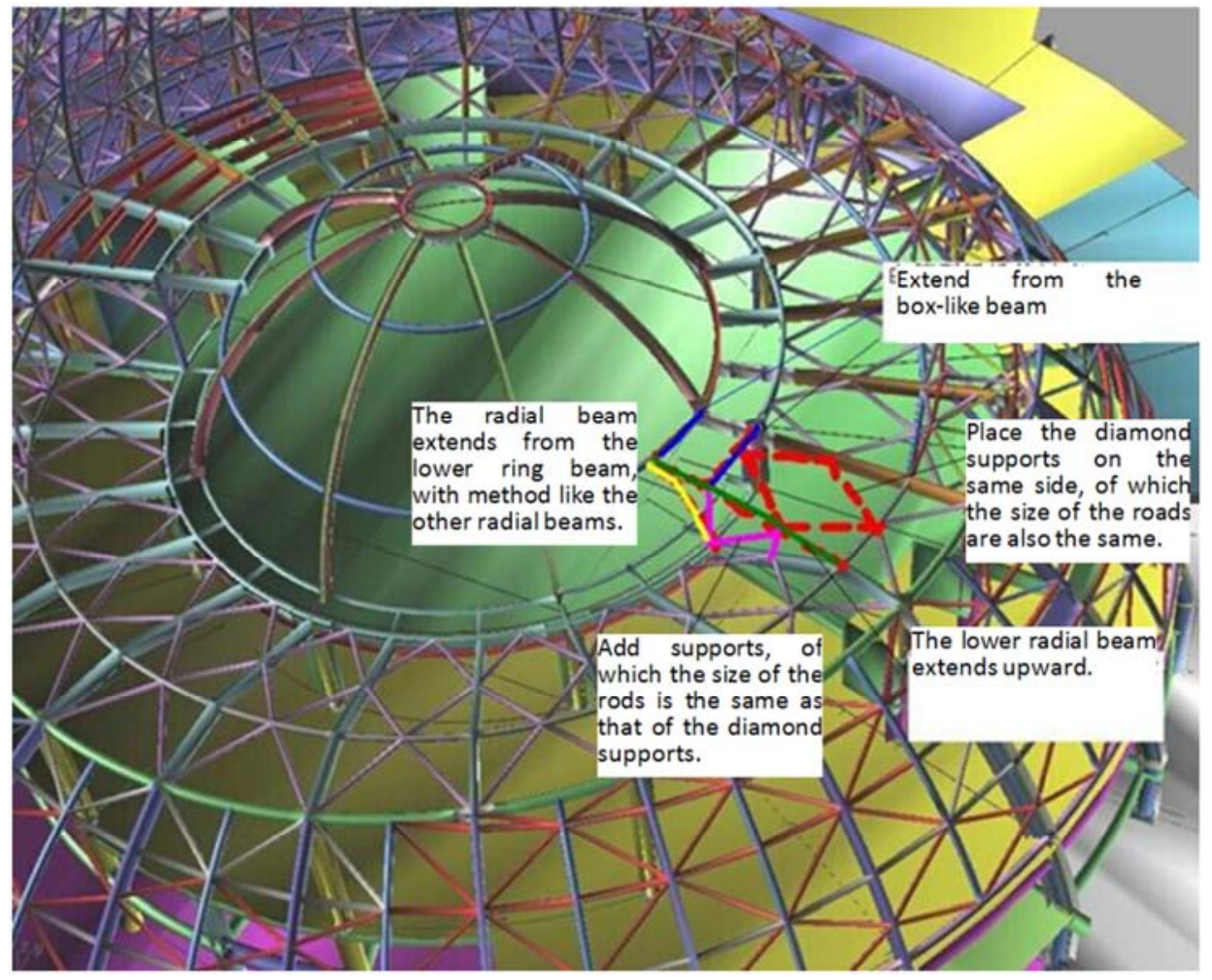

e. Missing of local rods in steel structure system.

Figure 5. Some problems in models.

The establishment of the modeling makes the communication with the design more convenient. Through the roaming function, the entire structural system is displayed to the designers intuitively, especially for the problem part, so that the designer can easily find out the cause of the problem and modify the direction. Take the problem above for example. The entire steel structure system can be easily perfected by offsetting the coordinates again, deleting the redundant components, extending the bearing carriers to the lower support, and adding the missing rods.

\subsection{Problems Found and Solved After Adding Concrete Models into Steel Structure Models}

In the Project, the design of the steel structure profession and the concrete structure profession are from different teams where different calculating software is used and the independent calculation model of their own is established in the design. Therefore, the contradiction between the two professions is unavoidable. Only by using BIM technology during the deepening of the drawing to merge the two models will the problems be more intuitive to be found out $[3,6]$.

\subsubsection{Adjustment of Base in Steel Structure Column}

Due to the architecture requirements, the top surface of the ground beam is higher than the height of the bearing platform. However, the column foot of the steel structure is located on the top surface of the bearing platform, therefore, the upper reinforcement of the ring ground beam and the radial ground beam just intersect at the column foot. Since the reinforcement of the ring ground beam needs to pass through the web of the column and the floor of the column foot, which will greatly 
weaken the strength of the steel column, it is necessary to reinforce the column foot of the steel column's web, etc. While the reinforcement of the radial ground beam needs to be connected to the flange plates of the steel column through the reinforcement, the presence of these connecting plates makes it impossible for the vertical main reinforcement of the civil column to pass through. After consultation with the relevant parties, it is determined that the column foot should be raised above the ground beam so that the reinforcement of the ground beam would pass through the lower part of the column foot. Because it is an arc column, part of the column foot has been moved to the outside of the bearing platform after being raised, causing that anchor bars cannot be embedded (as shown in Figure 6). After another discussion, the underground part of the column foot is changed to a straight section (as shown in Figure 7), so as to keep the concrete part of the steel column on the ground as the shape originally designed. [10]

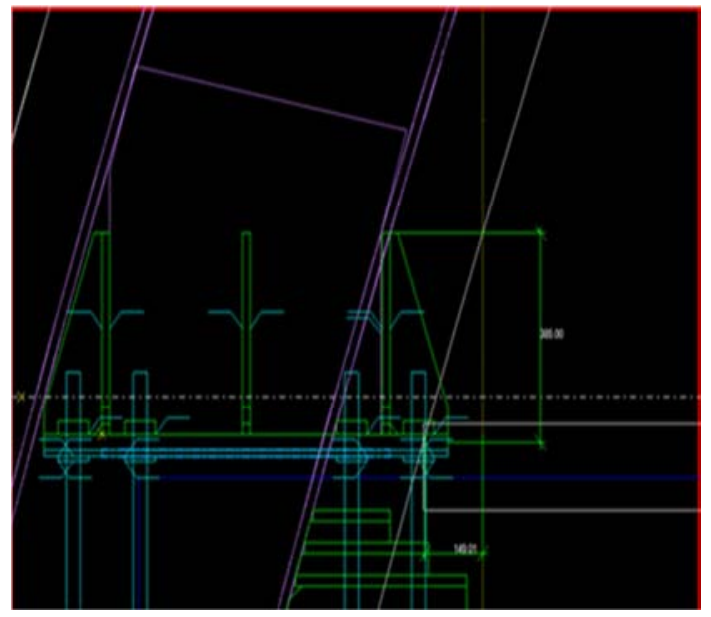

Figure 6. Column foot offset cap.

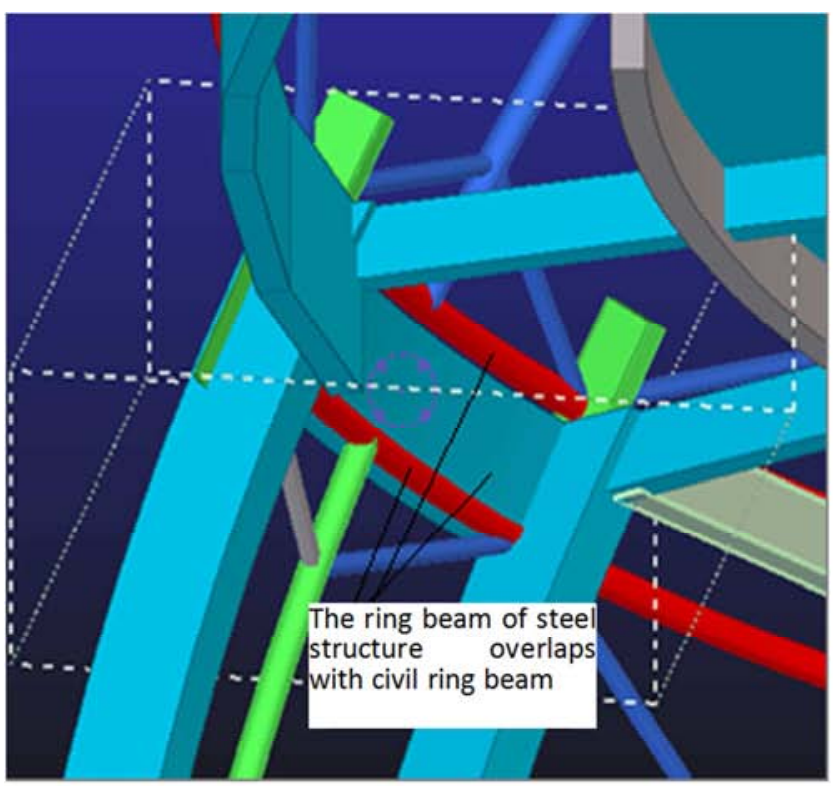

a. Collision 1

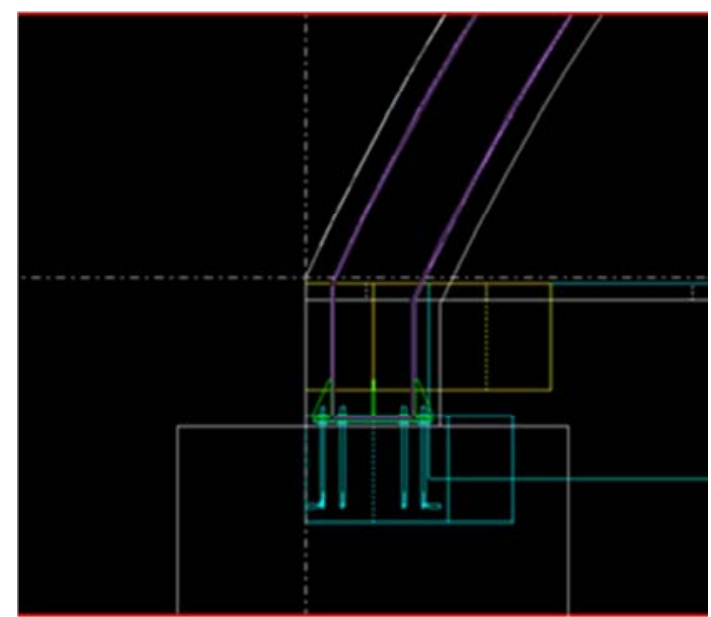

Figure 7. Underground part of steel column change into straight section.

\subsubsection{Collision of Horizontal Components in Steel Structure with Horizontal Components in Concrete}

This situation occurs in large numbers on the position where the steel-reinforced concrete structure is converted to clean steel structure. The first is on the position where the components of the ring circular steel pipe on the shell of the structure overlap with the edge ring beam of the concrete floor or the concrete ring beam, as shown in Figure 8a; the second is at the junction between the two different structures including steel structure and concrete structure on the floor, where the ring beam of the steel structure collides with the ring beam of the steel structure, as shown in Figure 8b; the third is when the horizontal components of the steel structure and the horizontal components of the concrete present at the same time [5].

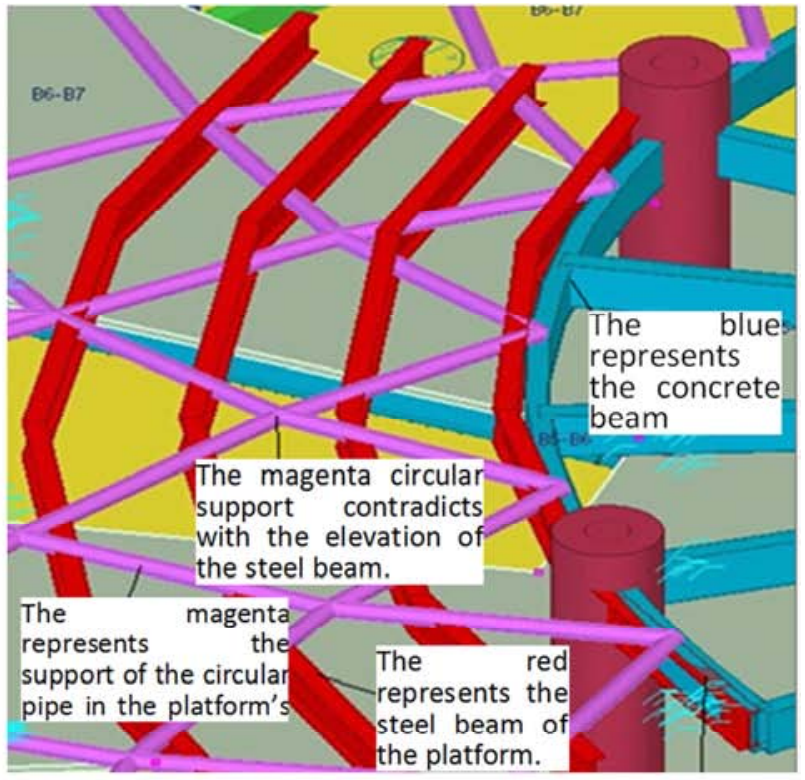

b. Collision 2

Figure 8. Collision of horizontal components at the junction of different structure forms. 
For the first situation, the ring steel pipes are used to support the vertical arc pipes and also these two pipes are the supporting points of the slant support pipe. However, all of these pipes are provided for the curtain wall keel, so even if such overlaps occur, it is also not possible to remove these pipes, but to adopt a method to appropriately raise or lower the ring steel pipe components so as to avoid the concrete ring beams. Considering the construction of the ring beams in advance, the distance between the steel pipe after being raised or lowered and the concrete beam shall ensure the operating space for the welding of the steel pipe and the column. In the
Project, a net distance of $200 \mathrm{~mm}$ has been set between the steel pipe and the concrete beam.

The occurrence of the latter two situations is due to the fact that both structures are required in design. It is determined after the research with the designers from the two professions that the concrete ring beam should be merged with the ring beam of the steel structure to a steel-reinforced concrete ring beam (shown in Figure 9), which does not only ensure the integrity of the two structural systems, but also makes the construction of steel structures more convenient.

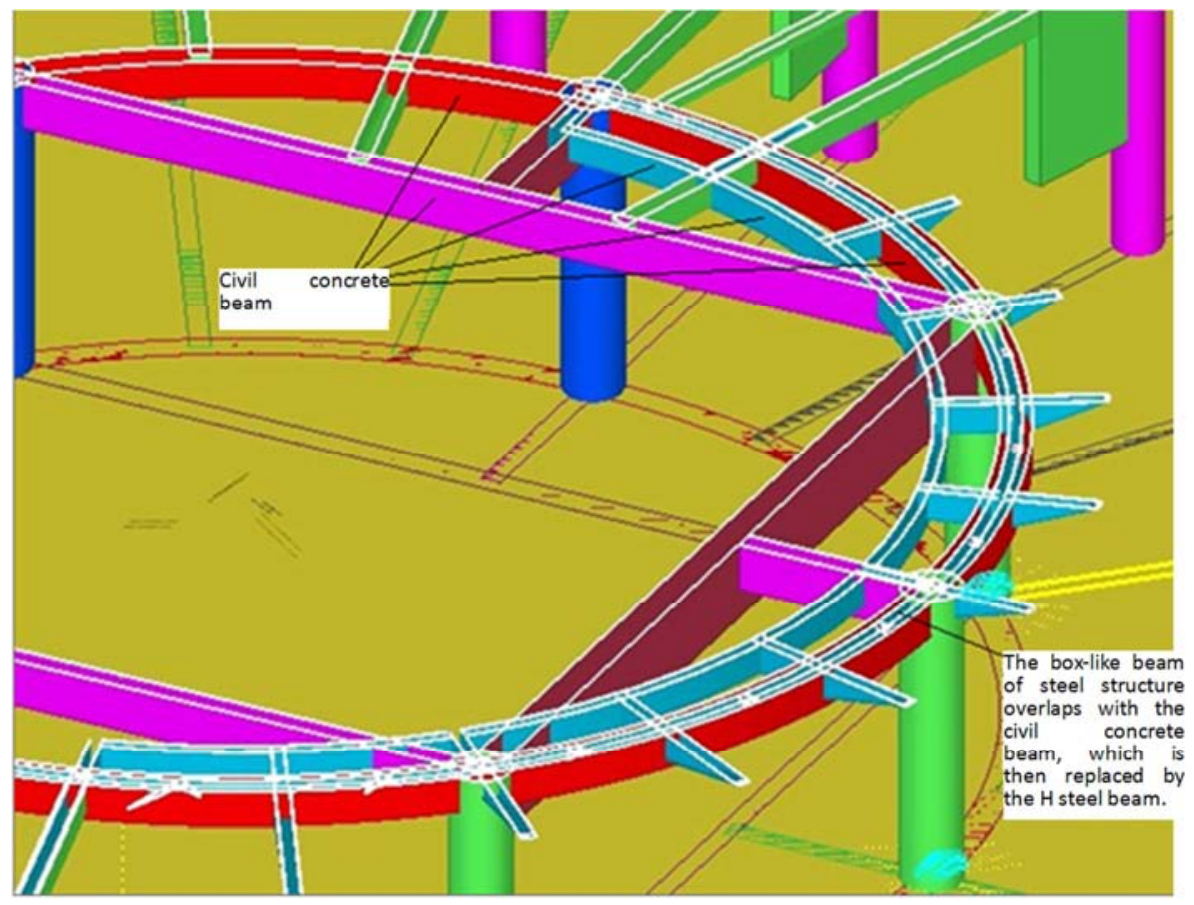

Figure 9. Setting steel ring beam between local concrete ring beams.

\subsubsection{Influence of Steel Structure Components on Concrete Components}

Figure $8 \mathrm{a}$ has shown the situation where multiple steel structure pipes pass through the concrete ring beam, which has occurred in many places. The intersection of these components makes the reinforcement of the concrete components unable to pass, which has destroyed the concrete structure system, thus affecting the structural stress and making it difficult for the

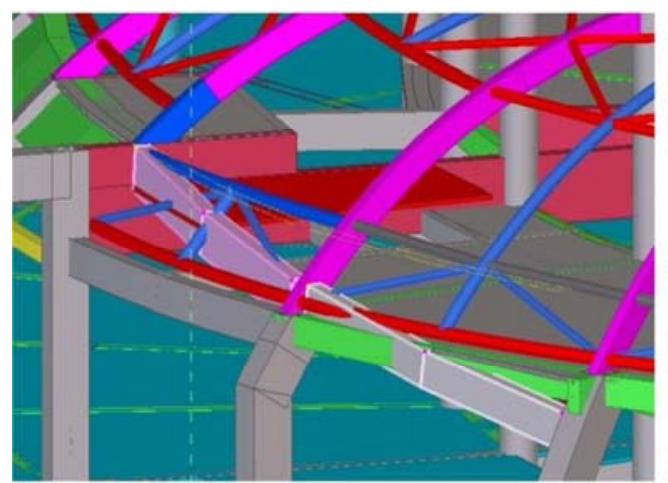

formwork processing and installation. Therefore, the method of changing the elevation of steel components is adopted in the design to avoid concrete components; Figure 10 shows that the elevation of the top surface of the box-like beam in the steel structure exceeds the elevation of the concrete floorboard, so that the continuous slab of the floor concrete is no longer continuous, which is also handled in the way of lowering the elevation of the steel components.

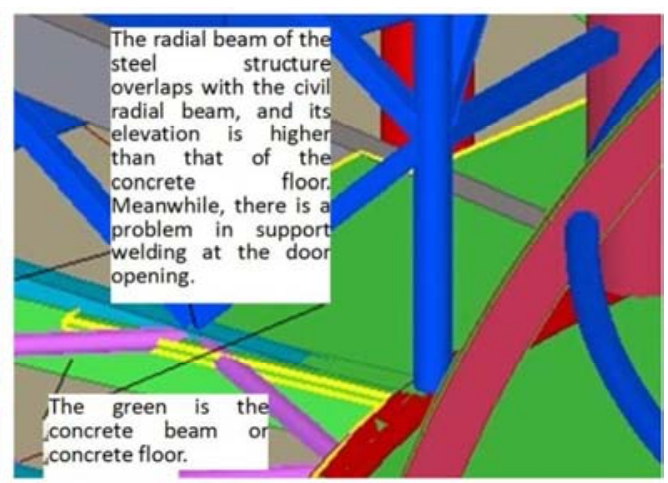

Figure 10. Steel components barrier concrete structure. 


\subsubsection{Setting Up Transitional Embedded Parts}

Through establishing the overall modeling of the structure, it is found that after the support pipe on the lower shell is intersected with the steel reinforcement's web of the steel-reinforced concrete arc column, since there is a certain distance between the joints and the outer surface of the concrete column and an obvious "V" fold is formed in each joint with the number of such more than 200 (shown in Figure $3 b$ ), they do not only affect overall rounded appearance, but also make the installation of curtain wall keel difficult, and more importantly, the subsequent construction of concrete works is more difficult [4].

1) Process influence problem: the lower shell is a steel-reinforced concrete structure. After the skeleton of the steel reinforcement is installed, the installation of a large number of support components between the columns will take a large amount of space and a long time, making the reinforcement, formwork and formwork support of the concrete works and even concrete pouring unable to be carried out [1].

2) Joint processing problem: in the joints where the support components are connected to the steel reinforcement, the longitudinal reinforcements and stirrups of the steel-reinforced concrete columns cannot pass because the specifications of the support components are relatively large (with diameter between 219 and 402); it is also a problem, namely, how to pour concrete into the interior of the support pipe to ensure the overall strength of the steel column; the variability in specifications and angles of the support pipes makes it difficult to process and to install the formwork at each joint [2].

3) Aesthetic problem: the steel support connected to the steel-reinforced concrete arc column supports each span to form an obvious "V" fold. However, the upper half of the support is connected to an arc box-like column of steel structure, and the end where it is connected to the box-like column can be closer to the surface of the shell, which makes the horizontal and slant support of the upper and lower half of the shell inconsistent in fluctuation amplitude, thus affecting the perception. Finally, as the attachment point of the curtain wall base, the amplitude of the "V" fold has exceeded the adjustment range of the curtain wall connector to deviation of the datum plane, which has greatly increased the installation difficulty of the curtain wall keel.

In summary, the installation of a large number of column support members is a process on critical path, which will directly affect the schedule of the entire project, and the joint processing method is a complicated technical problem. After in-depth discussion and comparison, the final choice is to set up transitional embedded parts (see Figure 11). The embedded part is provided with a pre-embedded plate on the upper and both sides of the steel-reinforced concrete column, of which the pre-embedded plate is connected with the steel-reinforced column through the floor where the reinforcement clearing hole and concrete perfusion hole are arranged to ensure the banding of stirrups. The closing weld is carried out on the pre-embedded plate above after the stirrups are completed, and the plate is used as a pre-embedded part of the curtain wall, while the two embedded plates on the column side serve as connecting plates for the support pipes. Through such embedment arrangement, not only is the problem of embedded parts of the curtain wall solved, but also the installation of the column support and the concrete construction of the steel column are completely separated, and there is no problem of cross-operation affecting each other, thus saving costs, saving time and reducing safety risk.
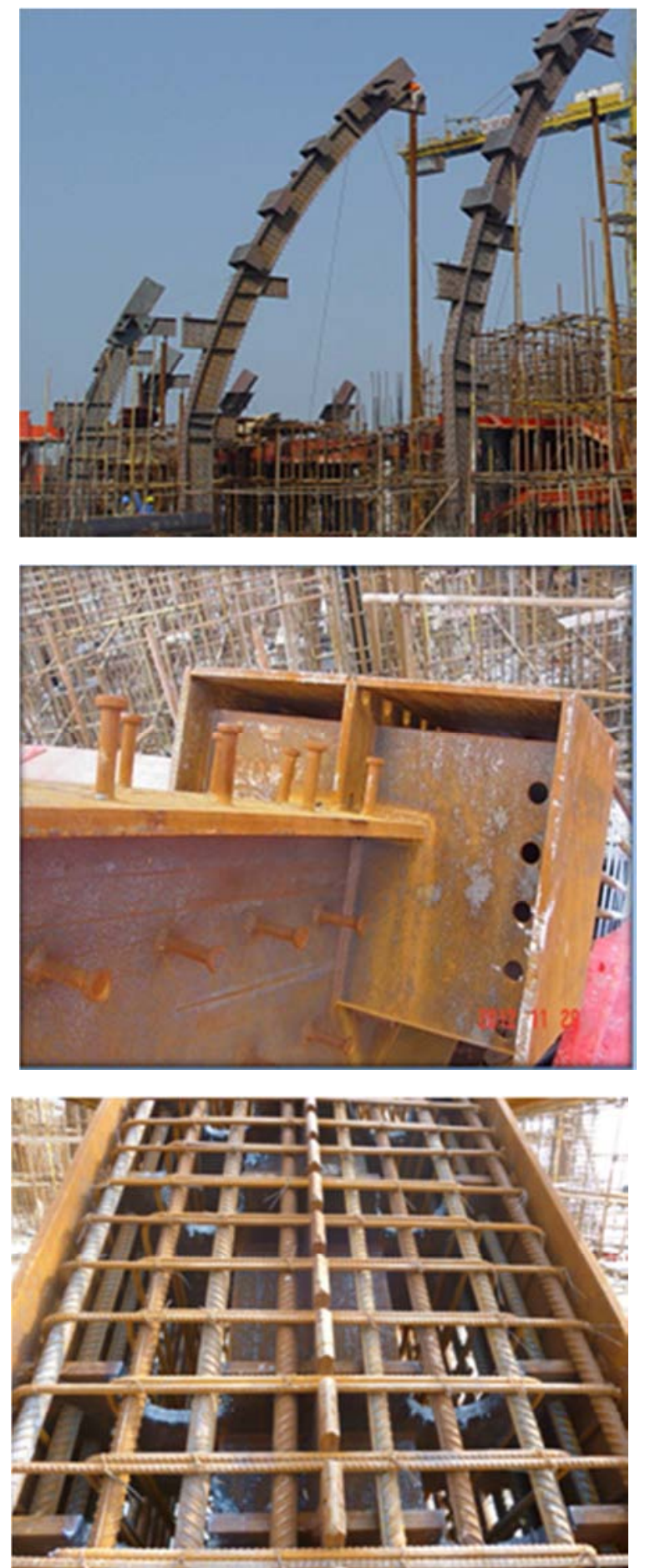


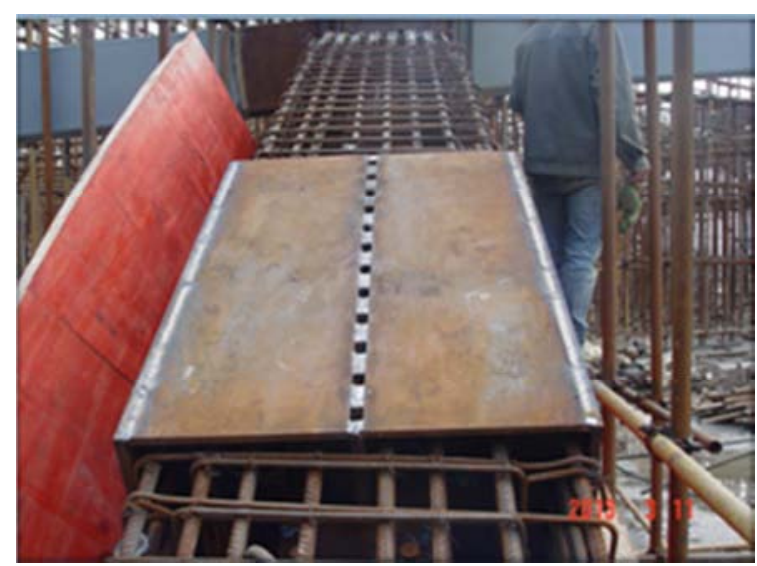

Figure 11. Transition of embedded inserts.

\subsection{Comparison Between Steel Structure Modeling and Architectural Modeling}

In this project, the architects depict the layout, function zoning and appearance modeling of the entire architectural complex according to their own conceptions and assumptions, while the engineers perform the structural configuration according to the architecture requirements. Because the interior of this architecture needs to meet the requirements for special use function such as long span and large space and the outside needs to meet the shape of the bionic organism, it is difficult to achieve the architects' requirements and intentions by only relying on the ordinary reinforced concrete structure. Therefore, the combination of the three structures including reinforced concrete, steel-reinforced concrete and steel structure is adopted in the structural configuration.

Because the design in different profession is from different teams, it is inevitable that there will be deviations in summarizing and linking the results. However, this deviation is difficult to find only by the comparison between the structural drawing and the architectural drawing, because this comparison is limited to the floor plan and the profile of typical position. To avoid the contradiction between the structure and the architecture so as not to affect the use function or result in deviation of modeling, we use the BIM whole modeling technology to build the structure and architecture of the entire architecture into two whole models. After the assembly, we use the rhinoceros to slice horizontally, and closely observe the relationship between the structure section and the architecture profile in the sliced slices. In this process, the contradiction between architecture and structure profession is exposed, for example, the individual rods in the truss of steel structure appear at the door opening; within a certain area, the external profile of the steel structure is $200 \mathrm{~mm}$ higher than that of the architecture design.

In order not to affect the use function, the steel structure designers have modified the truss structure to avoid the location of the door opening. In order to achieve the original design effect, the curvature of the steel structure rods can be reduced in the protruding area of the steel structure so as to make the structure meet the requirements of the architecture. [11]

\subsection{Fitting of Steel Structure Models and Curtain Wall Models}

The shape accuracy of the curtain wall, that is, the shell of the project, which is made of titanium plate, is something that can best express what the architects pursue for overall effect. The overall skeleton of the curtain wall, that is, the positioning of the structural part, is determined by the three-dimensional coordinates of a series of element points derived from the surface of the curtain wall depicted by the architect and shifted by $600 \mathrm{~mm}$. In the derivation of the coordinates and the fitting of curve of the structural profile bar, there is inevitably a deviation from the architectural assumption. With such a complex modeling, the datum plane required by the keel cannot be measured in real time on the site, but can only rely on the steel structure modeling and installation accuracy of the steel structure to ensure. Therefore, it is particularly important for the overall structural modeling, especially the "assembly" of the bar on the outer contour of the structure with the curtain wall modeling. In the early-stage preparatory phase of the project, after the professional modeling of the curtain wall is completed, in order to ensure the minimum space required for the functional layers such as the curtain wall keel, insulating layer and waterproof layer, etc., we will move the surface of the curtain wall by $600 \mathrm{~mm}$ to rebuild the modeling which is used to fit with the structural model to check whether the structure can meet the requirements of the curtain wall. As a result, it is found that many rods have exceeded the minimum space requirement for the curtain wall.

In order to ensure the smooth installation of the curtain wall, according to the results of the modeling fitting, the deviation data of the related bars which are readjusted correspondingly are derived. Finally, from the design model, the structure and architecture are perfectly unified.

The titanium plate of the curtain wall works assembled from more than 15,000 titanium plates in the Project covers 19,000 square meters. With such a complex outer contour, if there is no BIM system to find and solve the problem in advance, the conch finally formed would be a "geek", and on the other hand, the coordinate of each bearing shall be measured on site to ensure that the joint close of the plates are tight. However, such workload requires at least hundreds of thousands of labor costs, and even the coordinates of some parts are difficult to measure, so that the schedule will be relatively delayed for more than 3 months. The resulting increase in the cost from renting the tower cranes will exceed RMB 400,000 and it will be difficult to estimate the cost of material turnover, increase in management costs, and even fines from project delay. If some of the plates are scrapped due to measurement errors, the cost of each plate is close to RMB 5,000 , and since these plates come from abroad, if you want to add purchases, the schedule and cost will be more difficult to estimate.

\section{Conclusion}

The project of Ningbo-China Port Museum and National 
Underwater Cultural Heritage Protection Center, Ningbo Base, is a typical biotic architecture with a complex structure and unique shape, which has high accuracy requirements for the processing and installation of components. In view of the features and difficulties of this project, BIM technology has been used to start with the overall modeling of the steel structure and by coordinating with the civil engineering, architecture, curtain wall and other related professions, it has exchanged and demonstrated with the related professions from the joint design many times and has performed overall fitting and comparison on the model several times to have effectively eliminated the original error in the design and ensured the accuracy of the structure, so that the entire engineering error has been in the control range to reach the expected effect.

\section{References}

[1] Code for Construction of Steel Structures: GB50755-2012 [S] Beijing: China Architecture \& Building Press, 2012.

[2] Research Bureau of Architectural Science of Ministry of Heavy Industry, Research Institute of Construction of Ministry of Heavy Industry. Code for Acceptance of Construction Quality of Steel Structures: GB 50205-2001 (S). Beijing: China Planning Press, 2002.

[3] Zhang Jianhua, Liu Qiang and Zhang Mi, et al. Research of Owner Dominated BIM Application in Shanghai International Financial Center Project [J]. Construction Technology, 2015. 44 (6): 29-34.

[4] Liu Zhansheng, Ma Jinshu and Wei Qixing, et al. Applied Research of BIM Technology on Construction Management of Xuzhou Olympic Sports Center Stadium [J]. Construction Technology, 2015. 44 (6): 35-39.
[5] Zhao Xuefeng, Yao Aijun and Liu Dongming, et al. Application of BIM Technology in China Zun Tower Foundation Engineering [J]. Construction Technology, 2015, 44 (6): 49-53.

[6] He Jianjun, Qian Manzu and Chen Xinxi, et al. BIM Technology Application of Working Surface Division in China Expo Exhibition Complex Project [J]. Construction Technology, 2015, 44(6): 46-48.

[7] Dong Litao, Xu Hantao and Cao Le, et al. BIM Application in The Construction of Stiff Columns of WuHan Greenland Center [J]. Joumal of Information Technology in Civil Engineering and Architcture, 2015, 7(4):41-43

[8] Li Xiangjin, Xu Jun, et al. Construction Project Information Management based on BIM Model [J]. Joumal of Information Technology In Civil Engineering and Architcture, 2015, 7(6): 83-86.

[9] Chen Jiajia, Zhu Yan, et al. Application of BIM Technology in TianJin YongJi Garden II Phase [J]. Joumal of Information Technology In Civil Engineering and Architcture, 2015, 7(6):91-95.

[10] Jiao Ke, Yang Yuanfeng and Zhou Kaixuan, et al. Study on Whole Process of Structure Design Method based on BIM [J]. Joumal of Information Technology In Civil Engineering and Architcture, 2015, 7(5):1-7.

[11] Wang Yong, Li Jiulin and Zhang Jianping, et al. Research on Management Mechnaisim of BIM Model in Building Collaborative Design [J]. Joumal of Information Technology In Civil Engineering and Architcture, 2014, 6 (6):64-69.

[12] Chen Shun. Application of BIM Technique in Wu Han Center Project [J] Architecture Technology, 2014, 45 (12): 1127-1130. 